\title{
CONHECER AS REGRAS DO JOGO: UMA INTRODUÇÃO ÀS NORMAS PARA ESCRITA CIENTÍFICA DA AMERICAN PSYCHOLOGICAL ASSOCIATION ${ }^{1}$
}

\author{
Marília Prada ${ }^{2}$ \\ Margarida Vaz Garrido ${ }^{2}$
}

[Enviado a 31-03-2013. Aceite a 25-06-2013]

Resumo: O objectivo do presente artigo consiste em sistematizar as principais normas de escrita científica sugeridas pela American Psychological Association. Começaremos por rever, brevemente, o processo que levou ao desenvolvimento de tais normas e quais as vantagens inerentes à sua utilização. Seguidamente, descrevemos e ilustramos as orientações relativas ao estilo geral de escrita e formatação, estrutura e conteúdo de artigos científicos, as directrizes para elaboração de quadros e figuras e ainda as regras para elaboração das referências e de citação das fontes consultadas.

Palavras-chave: normas APA; estilo APA; referências bibliográficas.

Knowing the rules of the game: An introduction to the scientific writing guidelines of the American Psychological Association (Abstract): The purpose of this article is to systematize the main guidelines of scientific writing suggested by the American Psychological Association. We begin by briefly reviewing the process that led to the development of such guidelines and the advantages of using them. Then we describe and illustrate the guidelines regarding the general writing and formatting styles, structure and content of scientific papers, preparation of tables and figures, references and source citations.

Key-words: APA guidelines; APA style; bibliographic references.

\footnotetext{
${ }^{1} \mathrm{O}$ presente artigo foi preparado com o apoio da Fundação para a Ciência e Tecnologia (PTDC/PSI/PSO/099346/2008) e de uma bolsa Marie Curie (Intra European Fellowships FP7-PEOPLE-2011-IEF Grant Agreement Number 301410) atribuídos à segunda autora. As autoras agradecem os comentários e sugestões realizados pela equipa editorial da revista PSICOLOGIA a versões anteriores a este manuscrito.

2 Instituto Universitário de Lisboa (ISCTE-IUL), Cis-IUL. A correspondência relativa a este artigo deverá ser endereçada a Marília Prada, DEPSO, ISCTE-IUL, Avenida das Forças Armadas, 110, 1649-026, Lisboa, Portugal. Email: marilia_prada@iscte.pt.
} 
Uma breve análise da história da ciência (Gribbin, 2005) sugere que o desenvolvimento e estabelecimento da psicologia como disciplina científica partilha muitas das características do desenvolvimento do próprio conhecimento científico. Tal como nas restantes ciências, o progresso científico em psicologia constitui um processo contínuo que, na maioria dos casos, não resulta de ideias isoladas de grandes génios criativos abençoados com intuições especiais sobre como a mente humana ou o comportamento social funcionam. Pelo contrário, a construção e consolidação de conhecimento científico é um processo cumulativo, frequentemente resultante de pequenas contribuições construídas sobre conhecimento prévio. Para que este conhecimento se possa ir progressivamente construindo é essencial que os investigadores divulguem a sua pesquisa junto da comunidade científica. Além disso, e a par de outras ciências, desde o seu início e até meados século passado, a psicologia foi-se desenvolvendo de forma relativamente lenta. A partir dessa altura o progresso tornou-se bastante mais rápido, levando ao desenvolvimento de um número impressionante de modelos, teorias e metodologias procurando estudar e explicar o comportamento humano. Este incremento exponencial em muito se ficou a dever às potencialidades, cada vez maiores, de disseminação da pesquisa, nomeadamente à mobilidade dos investigadores e sobretudo à possibilidade de o conhecimento que produzem ser tornado rapidamente acessível a um número virtualmente ilimitado de pessoas. Mas se por um lado é certo que peritos e leigos têm cada vez mais acesso à ciência, por outro esta pauta-se por padrões de qualidade continuamente mais exigentes e é divulgada através de meios que aplicam critérios cada vez mais selectivos.

No mundo académico há muito que as universidades reconhecem o seu papel não apenas como transmissoras, mas também como geradoras de conhecimento. No entanto, só mais recentemente se tornou imperativo que o conhecimento produzido por alunos, docentes e investigadores seja activamente disseminado em publicações científicas, assim como junto da sociedade em geral. Para acompanhar estas mudanças muitas universidades abordam já nos seus currículos competências associadas ao planeamento, condução, divulgação e análise de informação científica, tais como: ler cuidadosamente, pensar correctamente, argumentar logicamente e escrever claramente.

No presente artigo debruçamo-nos sobre uma destas competências - a escrita científica. Ou seja, a capacidade de redigir clara e adequadamente, ideias, pontos de vista, propostas ou resultados da pesquisa, num documento, artigo ou relatório que é ajustado a objectivos e grupos-alvo específicos. Para escrever adequadamente um artigo científico no âmbito da psicologia é essencial que o investigador/autor se familiarize com os critérios gerais de 
estilo e de formatação mais utilizados e reconhecidos pela comunidade científica. Neste artigo iremos centrar-nos sobretudo nas principais directrizes para escrita científica, definidas na $6^{\text {a }}$ edição do Manual de Normas de Publicação (2010a) da American Psychological Association (APA).

A APA é uma organização científica e profissional que, desde 1892, representa a psicologia nos EUA. Actualmente conta com cerca de 140.000 membros de todo o mundo, afirmando-se como a maior organização de psicólogos. A APA assume como missão contribuir para o avanço do desenvolvimento, comunicação e aplicação do conhecimento psicológico com vista a beneficiar a sociedade e melhorar a vida das pessoas (www.apa.org). Entre as contribuições mais relevantes para estudantes e profissionais de todas as nacionalidades, contam-se o Código de Ética (APA, 2010b), o centro de recursos (bases de dados como a PsycINFO ou PsycARTICLES), a edição de livros, revistas científicas e materiais multimédia de diferentes sub-áreas, e, obviamente, o Manual de Normas de Publicação (i.e., Publication Manual). Desde a sua primeira proposta - "Instructions in Regard to Preparation of Manuscript" (Bentley et al., 1929) - este manual tem como objectivo definir um conjunto de procedimentos aplicáveis aos diferentes componentes da escrita científica de forma a facilitar a comunicação. Porém, tanto o desenvolvimento da disciplina como o da tecnologia disponível ${ }^{3}$ foram exigindo constantes actualizações que fazem com que a edição actual (i.e., $6^{\text {a }}$ edição, APA, 2010a) seja bem mais extensa do que as sete páginas iniciais.

Hoje, este manual oferece a autores académicos orientações detalhadas acerca dos vários aspectos relativos à elaboração e submissão de artigos para publicação. São assim delineadas, de forma bastante aprofundada, directrizes claras acerca da estrutura, conteúdo e estilo de diversos tipos de trabalhos científicos na área da psicologia. Especificam-se também normas de formatação (texto, quadros e figuras), recomendações para evitar diferentes tipos de enviesamentos na forma de comunicar (e.g., a nível da descrição da amostra ou de resultados estatísticos) e ainda um sistema de referências e citações que permitem a localização directa das fontes consultadas.

Em Portugal, não temos conhecimento de uma versão de normas para a escrita científica em psicologia formalmente publicada. Porém, não podemos deixar de reconhecer o trabalho realizado por alguns colegas, na tradução e adaptação para língua portuguesa de algumas das normas do manual da APA, com vista a tornarem estas normas mais acessíveis aos alunos (e.g., Correia, Lima, Lopes, \& Mouro, 2010).

3 A evolução das normas da APA (e a interacção com a evolução da própria disciplina) é em si mesmo um tópico patente na literatura (e.g., Daniel \& Onwuegbuzie, 2007; Sigal \& Pettit, 2012). 
No presente artigo, começaremos assim por rever alguns aspectos aplicáveis à generalidade dos trabalhos realizados no âmbito da psicologia estilo de escrita, estrutura, conteúdo e formatação de um artigo científico. De seguida, focaremos em maior detalhe as normas relativas a citações e referências bibliográficas, no respeitante às tipologias de material bibliográfico mais comuns (não substituindo a consulta do manual para outros casos).

\section{Estilo de Escrita}

A APA sublinha a importância da continuidade e fluidez na apresentação de ideias ao longo do discurso, que deve ser claro mas também conciso. Regra geral deverá dizer-se apenas o que necessita ser dito, evitando redundâncias no esforço de ser mais enfático. Nos seguintes casos as palavras sublinhadas são redundantes, devendo, por isso, ser eliminadas: "Um total de 70 participantes"; "Quatro grupos diferentes"; "Absolutamente essencial"; "Sumariado brevemente" ou "... de tamanho pequeno". A continuidade de ideias é facilitada pelo recurso a elementos de ligação que sugerem tempo (e.g., enquanto, desde, de seguida), causalidade (e.g., logo, consequentemente), adição (e.g., adicionalmente, mais ainda) ou contraste (e.g., porém, contudo, mas).

Devem evitar-se termos ambíguos. Tal aplica-se quer a constructos do foro da psicologia (como "atitude" ou "inteligência", remetendo para a necessidade de definir de forma explícita os constructos a nível teórico e operacional), quer a quaisquer outros termos que confiram ambiguidade ao texto em geral. Por exemplo, quando utilizamos pronomes o seu referente deve ser óbvio (e.g., se dizemos que "tais resultados sugerem que..." deve ser evidente para o leitor quais são esses resultados).

As formas verbais devem ser utilizadas de modo consistente. Por exemplo, recorre-se a conjugações no passado na revisão de literatura (e.g., "Garrido, Lopes e Calheiros (2011) demonstraram que..."), na descrição do procedimento (e.g., "Os participantes visualizaram um vídeo...") ou dos resultados (e.g., "verificou-se uma diminuição significativa no nível de ansiedade"). Já o tempo presente serve, habitualmente, para discutir implicações dos resultados e para apresentar conclusões (e.g., "Os resultados do Estudo 2 sugerem/indicam que...").

Um equívoco comum é o de que deve ser utilizada a voz passiva (e.g., "Uma série de estudos foi conduzida com vista a...") com o objectivo de enfatizar a investigação. Antes, é recomendado utilizar a voz activa, referindo os autores (e.g., "Prada e Garcia-Marques (2008) conduziram uma série 
de estudos...") ou o respectivo pronome pessoal. ${ }^{4}$ De acordo com o estilo da APA, poderá utilizar-se os pronomes pessoais no singular e no plural (eu e nós, respectivamente) quando a referência é feita ao próprio (e.g., "Eu investiguei...") ou ao próprio e os seus co-autores (e.g., "Nós analisámos a literatura...")..$^{5}$ A utilização da voz activa é particularmente importante na descrição da metodologia, pois permite identificar claramente o sujeito da acção (e.g., "Realizámos duas entrevistas..." vs. "Os participantes responderam...").

Deve ainda atender-se ao tom do discurso. Ainda que a escrita científica não recorra aos mesmos mecanismos de estilo que a escrita literária, devemos procurar envolver o leitor e evitar que o texto seja enfadonho. $\mathrm{O}$ tom é particularmente relevante quando queremos contrastar posições de diferentes autores ou apontar críticas a trabalho prévio. Por exemplo, é adequado afirmar que "Palma, Garrido e Semin (2011) não exploraram a possibilidade de..." mas não que "Palma, Garrido e Semin (2011) ignoraram totalmente a possibilidade de...".

A utilização de itálico no corpo do texto deve ser pouco frequente, salvo na expressão de símbolos estatísticos e nas âncoras de uma escala de medida (e.g., "uma escala de 7 pontos que varia entre negativo e positivo"). Outras situações comuns em que se recomenda a utilização de itálico (apenas na primeira vez que o termo é mencionado) são a introdução de um termo novo, técnico, termo-chave ou de um termo estrangeiro que não seja de utilização corrente na língua do presente trabalho. Um critério para avaliar se o termo é de utilização corrente é verificar se ele integra o dicionário (e.g., termos como "online" ou "email" apesar de anglófonos integram já os dicionários de língua portuguesa dispensando o itálico). O itálico não deve ser usado como forma de enfatizar uma palavra ou expressão.

O domínio da escrita científica passa não só pelo domínio da língua em que se escreve (grafia, pontuação, gramática, etc.), mas também por conhecer a literatura da área com vista a utilizar a terminologia mais comum e adequada (e.g., na descrição da amostra é, actualmente, considerado mais correcto utilizar a expressão "participantes" em vez de "sujeitos").

\footnotetext{
${ }^{4}$ Note-se que tal não implica que todas as afirmações se iniciem desta forma e/ou que a citação dos autores faça sempre parte da narrativa. Ou seja, se desejarmos descrever um dado fenómeno podemos fazê-lo identificando apenas a fonte entre parêntesis, salientando assim as evidências e não os investigadores (ver secção "citações no texto").

5 Note-se, contudo, que a língua portuguesa (por oposição à inglesa) dispensa, habitualmente, a utilização dos pronomes pessoais (eu, nós) na conjugação de verbos na primeira pessoa (e.g., "a análise da literatura que realizámos").
} 


\section{Utilização de Abreviaturas}

A utilização de abreviaturas é útil caso se trate de termos muito extensos e/ou técnicos. Para tal, quando o termo é mencionado pela primeira deverá ser escrito por extenso indicando de seguida, entre parêntesis, a abreviatura correspondente. Por exemplo:

"De acordo com dados recolhidos pelo Instituto Nacional de Estatística (INE), os portugueses..."

É recomendável uma utilização moderada das abreviaturas, pois quando é excessiva dificulta a leitura (em particular se a familiaridade da(s) abreviatura(s) é reduzida para a generalidade dos leitores). Por outro lado, se a utilização de uma dada abreviatura é escassa (i.e., após introdução da abreviatura, o termo apenas é mencionado mais duas vezes no texto) o leitor pode não se lembrar a que correspondia a abreviatura, sendo preferível apresentar sempre o termo por extenso. Algumas abreviaturas, pela sua familiaridade, dispensam a expressão do conceito por extenso (e.g., QI). Independentemente da frequência de utilização, é essencial ser consistente (e.g., não alternar entre "tempo de resposta" e TR). É também frequente abreviar símbolos de unidades de medida, quando acompanhados por valores numéricos (e.g., "4 cm"; "30 s", "12 min", etc.), e termos estatísticos (apenas quando expressos entre parêntesis). Por exemplo, a referência à média é abreviada por $M$ e desvio-padrão por $D P$ (ou $S D$, em inglês, standard deviation).

O estilo APA contempla ainda a utilização de abreviaturas latinas com vista a contribuir para a fluidez do texto, devidamente acompanhadas de pontuação específica. Estas apenas devem ser usadas quando apresentadas entre parêntesis, sendo que no corpo do texto se recomenda utilizar a tradução das expressões. Uma excepção a esta regra é a abreviatura "et al." (correspondente a "e outros" ou "e colaboradores"), que tanto pode ser usada entre parêntesis como no texto. As abreviaturas latinas mais comuns (e respectivo significado em português e inglês) estão sistematizadas no Quadro 1.

\section{Quadro 1}

Significado das Abreviaturas Latinas mais Comuns em Português e Inglês

\begin{tabular}{lll}
\hline Abreviatura & Português & Inglês \\
\hline e.g., & por exemplo & for example \\
etc. & entre outros, e o resto & and so forth \\
i.e., & isto é & that is \\
viz., & nomeadamente & namely \\
vs. & contra, em oposição, em contraste & against \\
cf. & comparar, confrontar & compare \\
et al. & e outros, e colaboradores & and others, and colleagues \\
\hline
\end{tabular}




\section{Expressão de Números}

A regra geral para a expressão de números é a de que os compreendidos entre um e nove devem ser referidos por extenso (e.g., "dois participantes desistiram da experiência"), enquanto os números iguais ou superiores a 10 devem ser referidos pelo seu algarismo (e.g., "...15 participantes por condição experimental"). Algumas excepções a esta regra são quando: (a) o número inicia a frase (e.g., "Trinta [e não 30] participantes evidenciam..."); (b) a sua utilização é universalmente aceite (e.g., "os doze [e não 12] apóstolos"); e (c) o número representa tempo, datas, idades e pontos de uma escala, utilizando-se sempre o algarismo (e.g., "1h 34 min"; "às 12.30"; "crianças de 2 anos"; "escala de 7 pontos").

\section{Formatação do Texto}

As regras que apresentamos de seguida referem-se às normas gerais de formatação de um artigo que será proposto para publicação ${ }^{6}$, sendo que as excepções serão mencionadas sempre que pertinente.

Sumariamente, a APA recomenda: a utilização do tipo de letra Times New Roman (tamanho 12); espaçamento duplo entre linhas (excepto em quadros ou figuras onde se poderá usar espaçamento simples ou a um espaço e meio); definir como mínimo $2.54 \mathrm{~cm}$ em cada margem (excepto o cabeça1ho); texto alinhado à esquerda (i.e., não utilizar a opção de "justificar", a qual alinha o texto relativamente a ambas as margens); indentar a primeira linha de cada parágrafo e a primeira linha de cada nota de rodapé.

A página de capa é identificada pelo número um, o resumo com o número dois, o texto inicia-se na página número três, e assim sucessivamente, até à página de referências que se inicia numa página independente. Cada quadro e cada figura devem ser apresentados numa página independente (primeiro todos os quadros). Cada anexo tem também início numa página independente e, caso existam mais do que um, deve ser identificado através de letras (e.g., Anexo A, Anexo B).

É ainda relevante salientarmos que nem todas as regras se aplicam necessariamente a outros tipos de documentos como propostas, projectos, dissertações ou outros trabalhos académicos. Por exemplo, nestes casos é habitual justificar o texto e apresentar os quadros e figuras na posição a que correspondem no documento.

${ }^{6} \mathrm{Ou}$ seja, a formatação do texto que aqui descrevemos refere-se ao manuscrito que é submetido. O formato final do texto publicado poderá ser diferente da formatação do texto submetido em função das normas de formatação gráfica da publicação em questão. 


\section{Níveis de título}

A APA estipula um sistema de níveis de título com vista a diferenciar e classificar as diferentes secções de um artigo. Estes estabelecem a hierarquia de secções através do seu formato específico (e.g., tipo de alinhamento do texto, utilização de negrito ou itálico) e não através da associação do título a letras ou números (i.e., não é necessário incluir um número antes do título; como "2. Método", "2.1. Participantes", etc.). Especificamente, a APA prevê cinco níveis de títulos, sendo que todos os títulos do mesmo nível num dado documento assumem igual importância. Todas as secções principais (i.e., Método, Resultados, Discussão - excepto a introdução que, por se identificar claramente pela sua posição no manuscrito, dispensa o título) se iniciam no nível 1, utilizando os níveis subsequentes se necessário (apenas se recorre a subtítulos se, dentro dessa secção, incluímos pelo menos duas subsecções). O sistema de títulos encontra-se ilustrado no Quadro 2.

Quadro 2

Formatação para os Cinco Niveis de Título

\begin{tabular}{|c|c|c|}
\hline & $\begin{array}{l}\text { Nível de } \\
\text { Título }\end{array}$ & Formato \\
\hline & 1 & Centrado, Negrito, Maiúsculas e Minúsculas ${ }^{\mathrm{a}}$ \\
\hline & 2 & Alinhado à Esquerda, Negrito, Maiúsculas e Minúsculas ${ }^{a}$ \\
\hline & 3 & $\begin{array}{l}\text { Avanço pendente, negrito, minúsculas }{ }^{\mathrm{b}} \text {, termina com ponto } \\
\text { final. }\end{array}$ \\
\hline & 4 & $\begin{array}{l}\text { Avanço pendente, negrito, itálico, minúsculas }{ }^{\mathrm{b}} \text {, termina com } \\
\text { ponto final. }{ }^{\mathrm{c}}\end{array}$ \\
\hline & 5 & Avanço pendente, itálico, minúsculas ${ }^{\mathrm{b}}$, termina com ponto final. ${ }^{\mathbf{c}}$ \\
\hline \multirow[t]{4}{*}{ Nota. } & \multicolumn{2}{|c|}{$\begin{array}{l}\text { Adaptado de Publication Manual of the American Psychological Association (p. 62), de } \\
\text { APA, 2010, Washington, DC: Autor. Copyright } 2010 \text { da APA. }\end{array}$} \\
\hline & \multicolumn{2}{|c|}{$\begin{array}{l}\text { a Este formato - capitalização de título ou title case - refere-se à utilização de maiúsculas } \\
\text { no início de cada palavra (excepto preposições, artigos, etc.). }\end{array}$} \\
\hline & \multicolumn{2}{|c|}{$\begin{array}{l}{ }^{\mathrm{b}} \text { Neste formato apenas a primeira palavra do título é apresentada em maiúsculas, sendo } \\
\text { todas as restantes em minúsculas (excepto se corresponder a nomes próprios). }\end{array}$} \\
\hline & \multicolumn{2}{|c|}{${ }^{\mathrm{c}}$ Texto inicia-se a seguir ao ponto final (i.e., sem parágrafo como nos títulos de nível 1 e 2) } \\
\hline
\end{tabular}

Sublinhamos que nunca se altera o tipo ou tamanho de letra dos títulos e que estes dispensam qualquer numeração. Quando o título é de nível 3, 4 ou 5 , o texto da secção inicia-se logo a seguir ao ponto final do próprio título (ou seja, não se faz parágrafo). Vejamos na Figura 1 um exemplo de diferentes secções de um artigo empírico, no qual indicamos, entre parêntesis, o nível de cada título. 


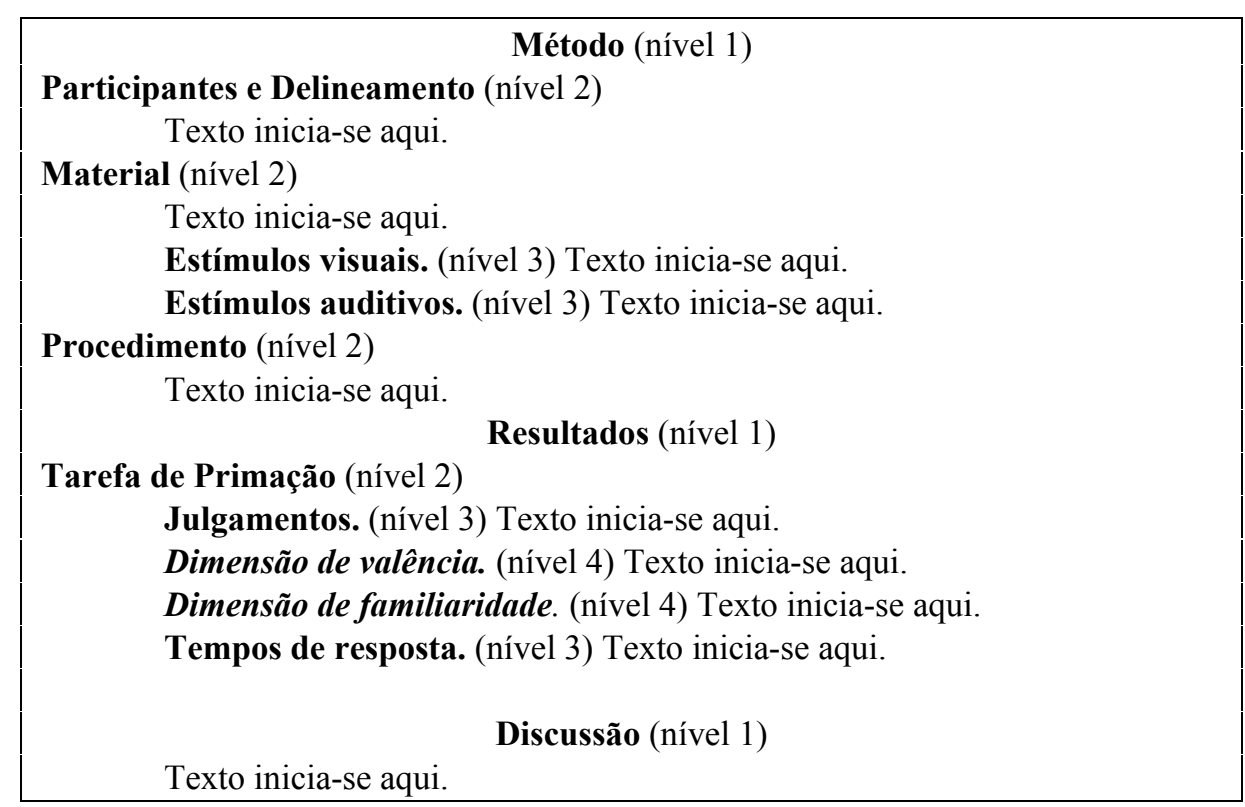

Figura 1. Ilustração dos cinco níveis de título.

\section{Seriação}

A seriação é útil para sinalizar os pontos-chave numa dada secção, parágrafo ou frase e pode ser efectuada de várias formas. Tratando-se de uma série de frases independentes (e.g., passos de um procedimento), deve identificar-se cada frase por um número árabe seguido de um ponto (ausência de parêntesis), iniciando-se a primeira palavra com letra maiúscula e terminando a frase com ponto final (ou a pontuação adequada). Por exemplo:

O procedimento do Estudo 1 envolvia as seguintes fases:

1. Fase de treino ... [continuação do parágrafo].

2. Fase de avaliação das palavras-alvo ... [continuação do parágrafo].

3. Fase de avaliação das imagens-alvo ... [continuação do parágrafo].

4. Questões de controlo ... [continuação do parágrafo].

Neste exemplo, os números relacionam-se de facto com a ordem de tarefas executadas pelos participantes. Porém, por vezes, os itens da lista não seguem um critério ordinal (e.g., cronologia ou importância). Nesse caso, em 
vez de listas numeradas, pode utilizar-se marcas ou bullets (i.e., símbolos como pequenos traços, quadrados ou círculos). Por último, caso os elementos da série sejam apresentados enquanto parte integrante de uma mesma frase ou parágrafo, devem ser identificados com letras minúsculas compreendidas entre parêntesis e separados por vírgulas ou, caso o texto dos próprios elementos contenha alguma vírgula como no exemplo que se segue, pontos e vírgula:

Com base nestes resultados definimos três grupos: (a) baixa motivação, avaliação média inferior a 20; (b) motivação média, avaliação média compreendida entre 20 e 50; e (c) motivação elevada, avaliação média superior a 50.

\section{Notas de rodapé}

As notas de rodapé cumprem a função de fornecer informação suplementar (relevante, essencial e directa) ao texto que fortalece a linha de argumentação. Cada nota deve veicular uma única ideia num único parágrafo. Dado que quando numerosas se tornam um elemento distractivo, devem ser usadas com parcimónia. As notas devem ser identificadas com números árabes, em formato superior à linha, na sequência em que são mencionadas no texto (e.g., "...na literatura."1). Este é aliás o formato praticado pela função "inserir nota de rodapé" dos programas de processamento de texto (e.g., Microsoft Word). As notas de rodapé podem ser apresentadas no final de cada página ou, em alternativa, numa página independente a seguir às referências bibliográficas (utilizando por exemplo a função "inserir nota de fim" do processador de texto).

\section{Estrutura e Conteúdo de um Artigo Científico}

Podem ser identificados diferentes tipos de artigos científicos, nomeadamente: (a) estudos empíricos (i.e., apresentação de pesquisa original); (b) revisões de literatura que constituem avaliações críticas de material já publicado e incluem sínteses de pesquisa numa determinada área, e meta-análises que envolvem procedimentos estatísticos para combinar resultados de um conjunto de estudos acerca de um dado fenómeno; (c) artigos metodológicos (e.g., apresentação de novas abordagens metodológicas, ou modificação às já existentes, de recolha e/ou análise de dados); e (d) estudos de caso (apresentação dos materiais obtidos aquando do trabalho com um indivíduo, grupo, comunidade ou organização). Independentemente destas tipologias existem secções e elementos comuns à maioria dos artigos que descrevemos de seguida. 


\section{Capa}

Na capa encontramos os elementos que se seguem:

Running head. Consiste numa abreviatura do título (máximo de 50 caracteres incluindo letras, pontuação e espaços entre palavras) apresentada no cabeçalho de todas as páginas para identificar o artigo. Deve ser apresentado em maiúsculas e alinhado à esquerda. Por exemplo, no caso do presente artigo o título foi abreviado para "NORMAS DA APA PARA ESCRITA CIENTÍFICA". O número da página deve estar alinhado à direita na mesma linha do Running Head (tipo de letra Times New Roman, tamanho 12).

Título. Deve sumariar a ideia principal, consistindo numa afirmação concisa acerca do tópico identificando as variáveis (ou tópicos teóricos) abordados e a relação entre estes. Deverá evitar-se a utilização de expressões gerais (e.g., "um estudo sobre"; "uma investigação experimental de") e de abreviaturas. Regra geral, o título não deverá exceder as 12 palavras. Ainda que a APA não faça recomendações explícitas neste sentido, é comum a introdução de uma expressão com vista a tornar o título mais apelativo (e.g., "Qual é Coisa, Qual é Ela? Avaliação de Valência e Familiaridade de Imagens de Objectos Desconhecidos" - Prada \& Silva, 2010; "Women, Fire, and Dangerous Things: What Categories Reveal about the Mind" - Lakoff, 1987). A nível de formatação, o título posiciona-se na metade superior da página, centrado entre as margens, e as principais palavras devem iniciar-se por letra maiúscula.

Informação relativa aos autores. Para identificar cada autor deverá incluir-se o nome (próprio, sobrenome e, eventualmente, um nome do meio), e a sua afiliação (i.e., a instituição a que o(s) autor(es) pertencia(m) quando o trabalho foi realizado). Poderá incluir-se uma dupla afiliação para um mesmo autor apenas quando duas instituições contribuíram de forma substancial para a pesquisa (e.g., ISCTE-IUL \& Utrecht University). Cargos (e.g., Professor) e graus académicos (e.g., PhD) não deverão ser referidos. É importante ser consistente na forma de apresentação dos nomes do autor, para que todas as publicações de um mesmo autor lhe sejam sempre correctamente associadas.

Nota do autor. Uma vez que pode incluir diferentes tipos de informação, deve organizar-se na seguinte sequência de parágrafos: (a) identificação detalhada da afiliação do(s) autor(es) (e.g., departamento, universidade ou centro de investigação, etc.); (b) descrição de eventuais mudanças de afiliação subsequentes à realização do artigo em causa; (c) outras informações relevantes, circunstâncias especiais (e.g., se o manuscrito se baseia em dados já publicados) e/ou agradecimentos (financiamento; contributo ou apoio de colegas ou alunos na realização do trabalho ou na revisão de versões prévias 
do artigo, etc.); (d) contactos (morada institucional, email). Esta é a última secção da capa e inicia-se com o respectivo título (i.e., Nota do Autor), centrado. Cada parágrafo incluído é indentado. Um exemplo de capa de um manuscrito pode ser consultado na Figura 2.

Running head: NORMAS DE VALÊNCIA E DE CONTEÚDO ESPACIAL

Gostar ou Elevar...Eis a Questăo:

Normas de Valência e de Conteúdo Espacial de uma Lista de Palavras

Margarida V. Garrido, Catarina Azevedo, Marília Prada

Instituto Universitário de Lisboa (ISCTE-IUL) / Cis-IUL

Ana Sofia Santos

Faculdade de Psicologia, Universidade de Lisboa

\section{Nota do Autor:}

O presente artigo foi preparado com o apoio da Fundação para a Ciência e Tecnologia (PTDC/PSI/PSO/099346/2008) no àmbito de um projecto coordenado pela primeira autora.

A correspondència relativa a este artigo deverá ser dirigida a: Margarida Vaz Garrido;

Departamento de Psicologia Social e das Organizaçz̃es, Escola de Ciências Sociais e

Humanas, ISCTE - Instituto Universitário de Lisboa, Av. đas Forças Armadas, 1649-026

Lisboa; E-mail: margarida.garrido@iscte.pt

Figura 2. Ilustração da capa de um artigo submetido para publicação 


\section{Resumo}

O objectivo do resumo é fornecer uma síntese (tipicamente compreende entre 150 a 250 palavras) abrangente dos conteúdos do artigo. Tal como o título do artigo, permite que os interessados no documento o identifiquem (e recuperem) nas bases de pesquisa bibliográfica (e.g., http://search.ebscohost. $\mathrm{com} /$ ). É frequentemente apontado como o parágrafo mais "importante" do artigo, uma vez que é o que estabelece o primeiro contacto do leitor com o trabalho, servindo ainda de comparação com outros artigos. Um bom resumo é: (a) preciso, reflectindo de forma correcta o objectivo e conteúdo do artigo (se o estudo replica, ou estende, investigação prévia deverá citar-se esse trabalho - apelido do autor, ano); (b) não avaliativo, devendo descrever e não avaliar (e.g., "os resultados corroboram a hipótese" e não "os resultados são satisfatórios"); (c) coerente e fluente, utilizando linguagem clara e bem articulada, voz activa ("os autores apresentaram os resultados" em vez de "os resultados foram apresentados"), e o tempo presente para descrever conclusões ou dados com aplicabilidade e o passado para descrever variáveis manipuladas; (d) conciso, recorrendo a frases curtas e informativas, incluindo apenas os conceitos, evidências e implicações mais relevantes.

Os conteúdos a incluir num resumo dependem do tipo de artigo. De seguida descrevemos apenas os dois tipos mais comuns (artigos empíricos e de revisão de literatura). Num artigo empírico deve incluir-se: o problema investigado (se possível, expresso numa frase); descrição dos participantes (especificando apenas as características pertinentes para o estudo) e das características essenciais da metodologia; resultados-base (incluir magnitude do efeito, intervalos de confiança e/ou níveis de significância estatística, etc.); e, por último, as conclusões e potenciais implicações ou aplicações do estudo. Já num artigo de revisão de literatura (ou meta-análise), o resumo deve incluir: o problema (ou relação entre variáveis) analisado, os critérios de selecção dos artigos revistos, o(s) tipo(s) de participantes incluídos nos estudos originais, os principais resultados e eventuais moderadores dos efeitos, e as principais conclusões e implicações para a teoria e/ou prática.

A nível de formatação, o resumo inicia-se numa folha independente, o título (Resumo ou Abstract) é centrado, o texto constitui um único parágrafo e todas as linhas do resumo são alinhadas à esquerda (mesmo a primeira).

A inclusão de palavras-chave (keywords), ou seja, termos que directamente ajudam a identificar os conteúdos do artigo, é recomendável pois auxilia o editor da revista a que o artigo foi submetido a direccioná-lo para os revisores mais adequados. Adicionalmente, ao identificar os principais tópicos, potencia a probabilidade de o artigo ser encontrado em bases bibliográficas quando esses tópicos são pesquisados. 


\section{Introdução}

Em termos gerais, o objectivo da introdução consiste em apresentar o problema e descrever a estratégia utilizada para a sua investigação. Para tal é necessário rever a literatura que sustenta a linha de argumentação seguida no trabalho. A APA (2010a) recomenda a reflexão sobre uma série de questões a responder ao longo da introdução. Em particular: (a) porque é este problema importante ou relevante? (e.g., pretende contribuir para a clarificação de inconsistências na literatura ou para a resolução de um problema social); (b) como se relaciona o presente estudo ou trabalho com a literatura? (não implica apresentação de perspectiva histórica de investigação no campo, mas antes a análise crítica dos trabalhos directamente relacionados com o actual, tendo em consideração um critério de continuidade lógica); (c) quais são as hipóteses e os objectivos e respectiva ligação com a teoria?; (d) qual a relação entre as hipóteses e o delineamento da investigação?; e, por fim, (e) quais são as potenciais implicações teóricas e/ou práticas do estudo/trabalho?

Uma metáfora comum utilizada na redacção da introdução é a de um funil, sugerindo que o texto se deve iniciar pelos aspectos mais gerais e, progressivamente, avançar para os mais específicos. Relembramos que a introdução se inicia sempre na terceira página do manuscrito e que dispensa o título relativo à secção. Em vez disso, pode apresentar-se novamente o título do artigo, centrado e com as palavras principais em maiúsculas (e.g., Conhecer as Regras do Jogo: Uma Introdução às Normas para Escrita Científica da American Psychological Association).

\section{Método}

A secção metodológica descreve em detalhe como o estudo foi conduzido, incluindo definições teóricas e operacionais das variáveis consideradas. A descrição da metodologia depende largamente do tipo de estudo. Porém, apenas uma descrição completa possibilita que o leitor avalie a adequabilidade do método (e, em consequência, a fidelidade e validade dos resultados), e, potencialmente, replique o(s) estudo(s). Quando o método utilizado já se encontra descrito numa publicação anterior (independentemente de ser do mesmo autor) deverá citar-se essa fonte e fazer-se apenas uma sinopse. Tipicamente o método inclui as seguintes sub-secções:

Participantes e Delineamento. A identificação correcta da amostra é essencial para: (a) inferir acerca da generalização dos resultados, (b) comparar replicações, e (c) utilizar as evidências em revisões de literatura e meta-análises. As características a descrever dependem do estudo em causa, sen- 
do a idade e o sexo dos participantes as mais comuns. Em alguns estudos poderá ser relevante indicar também as habilitações literárias, grupo étnico ou racial, nível sócio-económico, orientação sexual, entre outras. Deve ainda ser explicitado o método de amostragem (e.g., aleatória, por conveniência) e se houve compensação pela participação (e.g., crédito parcial numa unidade curricular; algum tipo de pagamento, etc.). Caso os participantes tenham sido distribuídos por diferentes condições, é importante identificar o delineamento experimental, bem como o tipo de manipulação efectuada (i.e., entre ou intra-participantes - between ou within-participants, respectivamente) e, sempre que aplicável, como foi realizada a distribuição (e.g., aleatória).

Actualmente, é habitual mencionar ainda se o estudo foi aprovado pelo comité de ética da instituição ou centro de investigação e se os princípios éticos em vigor foram respeitados. Quanto à forma como os participantes em investigação científica devem ser tratados, tanto o código deontológico da APA (2010b) como o da Ordem dos Psicólogos Portugueses (2011) referem, entre outros, aspectos como: a participação voluntária e informada, anonimato e confidencialidade dos dados recolhidos, bem como o direito ao esclarecimento pós-investigação (debriefing). Algumas instituições possuem códigos deontológicos próprios que devem ser consultados e respeitados.

Material e Instrumentos. Deve incluir-se nesta secção a informação que constitui a definição de todas as medidas recolhidas, descrevendo não só o método para recolher dados (e.g., entrevistas, questionários, observação) como os métodos utilizados para garantir a qualidade das medidas. Especificamente, pode descrever-se instrumentos como escalas ou questionários. Caso estes sejam de outros autores, é relevante incluir: origem, número (e exemplos) de itens, a forma de cotação (em particular se existirem itens invertidos), descrição de qualidades psicométricas (verificadas no estudo original e na presente amostra). Caso seja construído, deverá indicar-se, para além das qualidades psicométricas, toda a informação que permita a sua reprodução.

No que diz respeito a material-estímulo utilizado, seja ele escrito ou de outra natureza (e.g., imagens, filmes, sons, odores, etc.), a sua descrição deve ser exaustiva o suficiente para possibilitar uma replicação. Caso a descrição do material e instrumentos seja muito extensa ou de natureza muito técnica poderá ser apresentada em anexo.

Procedimento. Esta secção inclui todos os detalhes das intervenções ou manipulações efectuadas, especificando todas as condições (incluindo a de controlo), tendo atenção de referir não só a forma (i.e., o "Como"), como também a sequência temporal dos eventos (i.e., o "Quando"). É frequente apresentar as instruções dadas aos participantes em forma sumária ou a sua reprodução textual, dependendo da sua especificidade. Se a apresentação dos estímulos, ou a recolha e registo de dados, envolve equipamentos (ou soft- 
ware) específicos deve incluir-se (no corpo do texto ou remeter para anexo) a descrição do modelo (ou versão) e outros detalhes técnicos pertinentes (e.g., parâmetros de medição). $\mathrm{O}$ contexto de intervenção ou manipulação (e.g., laboratório, sala de aula, espaço público, etc.) deve ser mencionado, bem como a quantidade e duração da exposição à intervenção ou manipulação (e.g., quantas sessões, duração de cada sessão) e a forma como foram agrupados os participantes (i.e., sessões de grupo com x elementos ou sessões individuais).

\section{Resultados}

Esta secção é obrigatória em artigos empíricos. Consiste na apresentação de um sumário dos dados recolhidos e das análises efectuadas a esses dados que são relevantes (mesmo os que são contra as predições) para o discurso que se segue. O nível de detalhe adequado é o que permite justificar as conclusões. A regra geral é a de que o autor deve pressupor que o leitor possui conhecimento avançado dos métodos estatísticos e, nesse sentido, não rever conceitos e procedimentos básicos.

Devido à enorme variedade de técnicas de análise, a APA não especifica um conjunto de estatísticas necessárias, mas recomenda a inclusão de aspectos como: verificação da manipulação; tamanho da amostra por célula experimental; média observada na célula (ou frequências em caso de variável categórica); desvio-padrão observado na célula; parâmetros inerentes aos testes estatísticos (e.g., $\mathrm{X}^{2}, t, F$ - valor do teste, graus de liberdade, $p$ value). Actualmente as exigências relativas aos detalhes estatísticos apresentados são cada vez maiores, sendo recomendável que os principais resultados sejam acompanhados, por exemplo, pela referência ao erro-padrão (standard error - SE) e à dimensão do efeito $\left(\eta^{2}\right)$. Na descrição de resultados, a APA afirma que a leitura de muitos dígitos é difícil e como tal sugere o arredondamento para duas casas decimais na generalidade dos casos (descrição de correlações, proporções, estatísticas inferenciais como Qui quadrado, teste $\mathrm{t}$ de Student ou ANOVA). No caso do $p$ value deve apresentar-se o valor exacto recorrendo a duas ou três casas decimais (e.g., $p=.042$ ), excepto se tal valor for inferior a .001 (assim sendo a expressão adequada é $p<.001 \mathrm{e}$ nunca, por exemplo, $p=.000$ ). Apenas se utiliza o zero antes da marca decimal quando o valor verificado é inferior a um, mas estatisticamente poderia ser superior. Por exemplo, tratando-se de um valor de desvio-padrão inferior a um deverá apresentar-se: $(D P=0.05)$. Em oposição, sendo um o valor máximo do $p$ value ou de uma correlação, dispensa-se o zero (e.g., $p=.05$ ou $r=.05$, respectivamente). A APA define que as casas decimais 
devem ser separadas por pontos. ${ }^{7}$ Note-se que antes e depois do sinal de igual existe um espaço. Para melhor ilustrar como se reportam os resultados apresentamos os seguintes exemplos (adaptados e traduzidos para português):

Exemplo 1: Apresentação de análise de correlação (Martins \& Calheiros, 2012)

A análise de correlação ... revela que as dimensões positiva e negativa não se encontram associadas $(r=.122, p>.05)$. Adicionalmente, os resultados demonstram que a SC negativa se correlaciona positivamente com a medida geral $(r=.711$, $p<.001)$.

Exemplo 2: Apresentação de análise de variância (Garrido, Garcia-Marques, \& Hamilton, 2012a)

Para a análise do número de itens recordados, computámos uma ANOVA de acordo com o delineamento 3 (condição pista: sem pistas, pistas standard, pistas graduais) x 4 (replicação do alvo: educador de infância, skinhead, programador de computadores, trabalhador das obras). Apenas foi detectado um efeito principal da condição pista. Este efeito principal, $F(2,46)=11.03 ; p<.001, \eta_{p}^{2}=.324$, MSE $=2.59$, revelou que as três condições de pista diferem significativamente $\left(M_{\text {sem pis- }}\right.$ tas $=5.47 ; \mathrm{M}_{\text {pistas standard }}=3.05 ; \mathrm{M}_{\text {pistas graduais }}=3.90$ ).

Exemplo 3: Apresentação de análise de regressão (Bernardes \& Lima, 2006) Com vista a explorar o poder preditivo da estratégia e das crenças de capacidade sobre crenças de controlo, realizámos análises de regressão múltipla hierárquica para cada tipo de causa e escalão etário. ... Como ilustrado no Quadro 3 ... apenas o efeito de interacção entre capacidade_sorte e escalão etário é significativo, $\Delta R^{2}=.06, F(1,180)=13.65, p<.001$.

Quadros e figuras. O recurso a quadros e figuras é mais frequente na secção de resultados, mas não é exclusivo. Pode, por exemplo, recorrer-se a uma figura para explicitar um modelo teórico complexo na secção de introdução ou um esquema de procedimento na secção de método. Por exemplo na Figura 3 está representado um esquema de procedimento de um experimento que decorre em duas fases (sendo que a primeira fase varia consoante a condição experimental e a segunda é comum às três condições). Note-se que o significado dos acrónimos que aparecem na figura (i.e., SOA e ITI) são explicitados no título.

\footnotetext{
${ }^{7}$ Ainda que para a língua portuguesa a regra defina antes a utilização de vírgula, por uma questão de uniformização do estilo de publicação não nos parece errado utilizar a regra de notação internacional.
} 


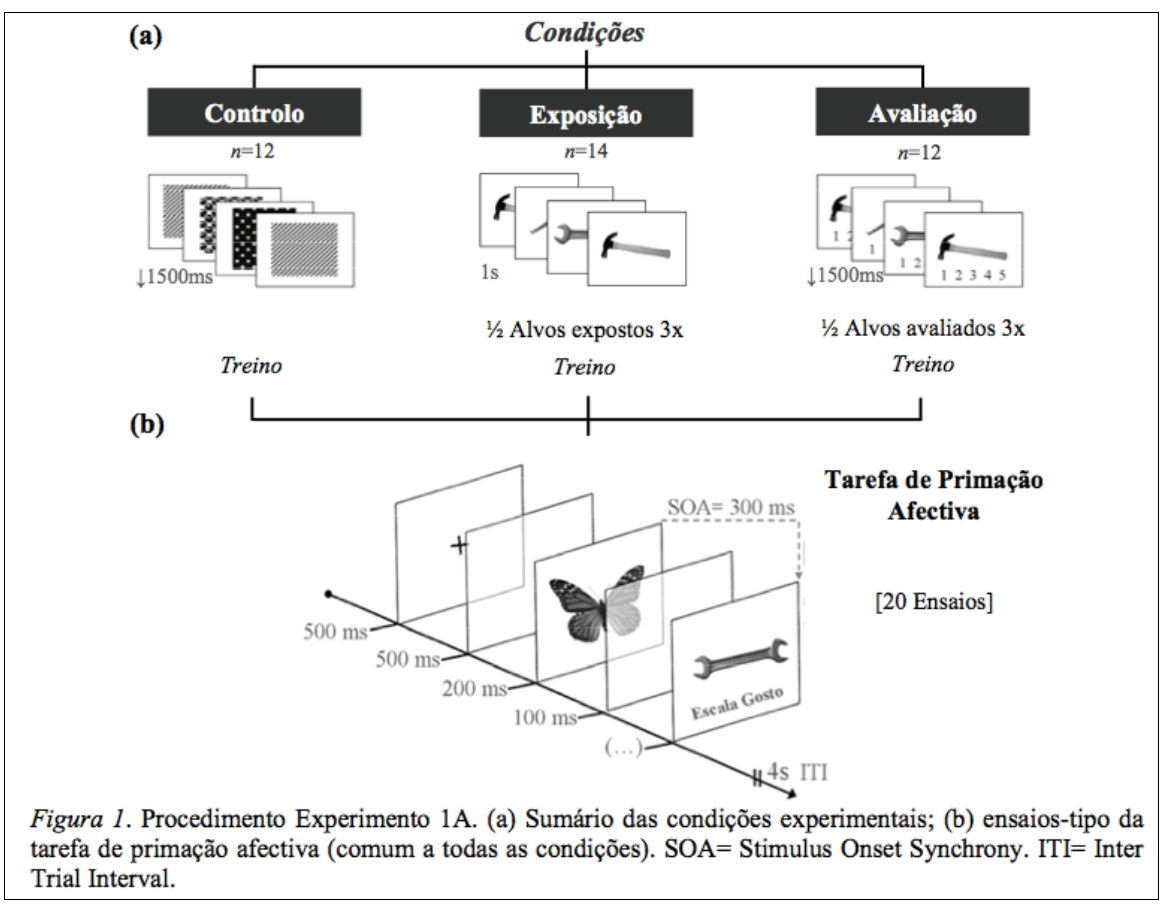

Figura 3. Exemplo de figura com ilustração de procedimento experimental. Retirado de Alvos em movimento: O papel das características dos estímulos na primação afectiva (p. 60) de M. Prada, 2010, Dissertação de Doutoramento, ISCTE-IUL, Lisboa, Portugal.

Independentemente da secção em que são apresentados, o objectivo principal dos quadros e figuras é o de ajudar o leitor a compreender informação extensa ou complexa. Assim sendo, só devem ser utilizados se forem efectivamente úteis (e.g., a apresentação de informação estatística relativa a variáveis sócio-demográficas como idade ou sexo dispensa, na generalidade dos casos, a utilização de quadros ou figuras, pois pode facilmente ser sintetizada numa única frase). Em todo o caso, deve evitar-se a redundância. $\mathrm{Ou}$ seja, nunca se deve apresentar um quadro e uma figura para ilustrar a mesma informação, tal como não se deve reproduzir de forma detalhada no texto a informação que estes contêm. Em vez disso, deve orientar-se o leitor na compreensão da informação que apresentam, identificando em que quadro ou figura esta está sintetizada, e salientando os pontos-chave.

Os quadros e figuras devem ser identificados com números de acordo com a ordem de referência no texto, utilizando letra maiúscula (e.g., Figura 1; Quadro 1). Para fazer referência no corpo do texto a uma dada figura ou 
quadro utiliza-se sempre a sua designação numérica, evitando expressões como "na figura acima" ou "no quadro da página 10" porque tais aspectos alteram-se com eventuais mudanças de paginação.

Quadros. As principais regras subjacentes à construção de quadros são a identificação das unidades de medida (não utilizar diferentes unidades de medida ou diferentes números de casas decimais numa mesma coluna) e a consistência na terminologia referente a um determinado fenómeno ou variável (e.g., usar "tempo de reacção" ou "tempo de resposta", mas não ambos). Recomenda-se o uso de duas casas decimais na apresentação dos dados. A nível gráfico, os quadros caracterizam-se pela ausência de linhas verticais. Os quadros são delimitados apenas por uma linha horizontal no topo e na base. O Quadro 3 constitui um exemplo realizado de acordo com estas normas gerais, mas contém algumas modificações que se prendem com as normas gráficas específicas da revista científica na qual o artigo foi publicado.

Como podemos observar no Quadro 3, após a identificação do quadro encontramos, na linha seguinte, o título onde é explicitado quer a variável medida (i.e., proporção de falsas memória) quer as manipuladas (i.e., tipo de lista e tipo de tarefa de memória). Note-se que o título deve ser apresentado em itálico, sem ponto final, e as principais palavras são apresentadas em maiúsculas $^{8}$. O cabeçalho das colunas é definido por uma linha horizontal inferior. No exemplo encontramos cinco colunas: uma relativa aos acertos verificados por tipo de item - "List items (Hits)" - e quatro referentes aos tipos de listas (i.e., "Social Negative", "Social Positive", etc.). Note-se que como na primeira coluna se apresentam os dados relativos a duas tarefas de memória (i.e., "Impression Formation" e "Memory"), os diferentes tipos de itens são apresentados de forma indentada de forma a potenciar a legibilidade.

Existem três tipos de notas que podem suceder à apresentação do quadro: (a) geral - aquela que qualifica, explica ou fornece informação partilhada por todas as células do quadro e que termina com a explicação de quaisquer abreviaturas ou símbolos, sendo introduzida pela expressão da palavra "Nota" (itálico, seguida de ponto final); (b) específica - informação que diz respeito apenas a uma coluna, linha ou célula específica do quadro, sendo cada nota deste tipo identificada por uma letra minúscula em texto superior à linha (e.g., ${ }^{\text {a,b,c }}$ ) e, por fim, (c) nota de probabilidades - indica como asteriscos ou outros símbolos são utilizados no quadro para indicar $p$ values e, consequentemente, os resultados de testes estatísticos. No Quadro 3 apenas está representada uma nota geral.

\footnotetext{
${ }^{8}$ As directrizes a este respeito são ilustradas no título do Quadro 3. Note-se que no título da "Table 1" são visíveis alterações de formatação de acordo com o manual de estilo da revista científica em questão. Como podemos observar nem sempre há uma correspondência total entre as normas da APA e as normas de cada revista.
} 
Quadro 3

Exemplo de Quadro que Sintetiza Informação Estatística

TABLE 1. Proportions of Different Types of False Memories by List

\begin{tabular}{|c|c|c|c|c|}
\hline \multirow[b]{2}{*}{ List Items (Hits) } & \multicolumn{4}{|c|}{ Lists } \\
\hline & Social Positive & Social Negative & $\begin{array}{r}\text { Intellectual } \\
\text { Positive }\end{array}$ & $\begin{array}{r}\text { Intellectual } \\
\text { Negative }\end{array}$ \\
\hline \multicolumn{5}{|l|}{ Impression Formation } \\
\hline Trait Items & .95 & .83 & .82 & .84 \\
\hline A-thematic Items & .75 & .74 & .82 & .81 \\
\hline \multicolumn{5}{|l|}{ False Memories } \\
\hline Social Positive & .40 & .00 & .07 & .04 \\
\hline Social Negative & .00 & .34 & .00 & .04 \\
\hline Intellectual Positive & .22 & .04 & .46 & .01 \\
\hline Intellectual Negative & .00 & .05 & .00 & .40 \\
\hline A-thematic Associates & .00 & .04 & .00 & .02 \\
\hline \multicolumn{5}{|l|}{ Memory } \\
\hline Trait Items & .90 & .84 & .80 & .81 \\
\hline A-thematic Items & .75 & .77 & .77 & .71 \\
\hline \multicolumn{5}{|l|}{ False Memories } \\
\hline Social Positive & .21 & .02 & .05 & .01 \\
\hline Social Negative & .00 & .30 & .01 & .06 \\
\hline Intellectual Positive & .23 & .03 & .31 & .06 \\
\hline Intellectual Negative & .00 & .17 & .01 & .32 \\
\hline A-thematic Associates & .06 & .06 & .01 & .04 \\
\hline
\end{tabular}

Nota. Retirado de "False Memories and Impressions of Personality", de L. Garcia-Marques, M. B. Ferreira, L. Nunes, M. V. Garrido, e T. Garcia-Marques, 2010, Social Cognition, 28, p. 563. Copyright 2010 de Guilford Publications.

Figuras. Contrariamente aos quadros, o título (i.e., descrição sumária da figura) sucede à apresentação das figuras e é apresentado imediatamente a seguir à identificação numérica da figura seguida de ponto final. As figuras semelhantes, ou de igual importância, devem ser do mesmo tamanho e escala. De facto, as figuras semelhantes podem mesmo ser combinadas (e.g., apresentar um gráfico de linhas acima, ou ao lado, de outro com eixos idênticos) numa figura única de forma a facilitar a comparação entre estas. A legibilidade é um critério essencial na preparação da figura. Assim sendo, a APA recomenda a utilização de tipos de letra simples (como Arial, Futura 
ou Helvetica) de tamanho compreendido entre 8 e 14 pontos, evitando o negrito. Tendo em conta que, habitualmente, os artigos são publicados a preto e branco, quando se escolhe o preenchimento das barras de um gráfico deve maximizar-se a diferença entre estas (e.g., no caso de serem dois tipos de barras recomenda-se uma a preto e outra a branco, ou seja, nesta última, apenas o seu contorno).

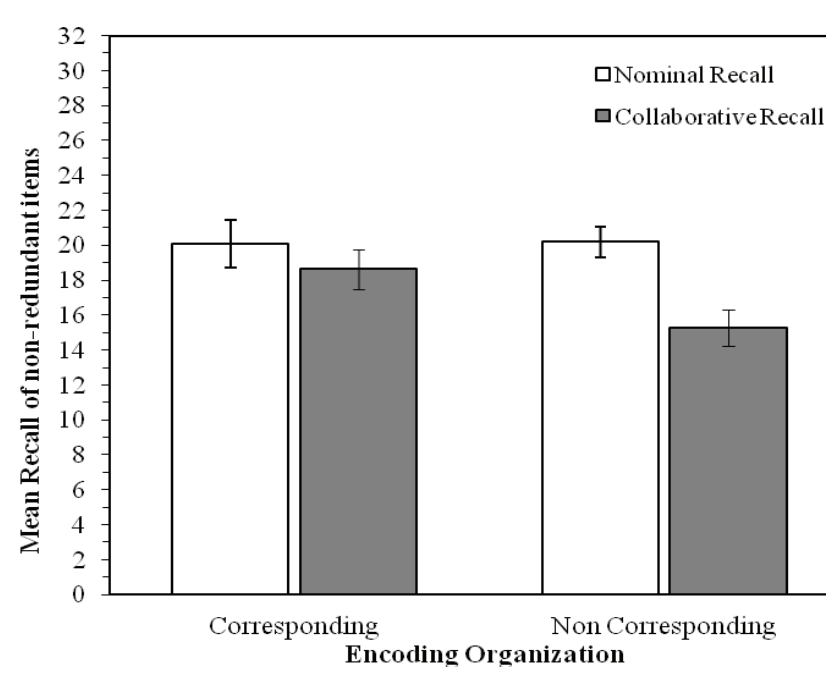

Figure 1. Mean recall of non-redundant items $(+S E)$ as a function of encoding organization and group recall condition

Figura 4. Exemplo de figura com ilustração de gráfico de barras. Retirado de "Effects of Correspondence between Encoding and Retrieval Organization in Social Memory" de L. Garcia-Marques, M. V. Garrido, Hamilton, D. L., e M. B. Ferreira, Journal of Experimental Social Psychology, 48, p. 204. Copyright 2012 de Academic Press Inc.

Como podemos observar na Figura 4, o título sintetiza a informação representada. De facto, a variável dependente (i.e., recordação média de itens não redundantes) está representada no eixo vertical (i.e., y). No eixo horizontal (i.e., $x$ ) estão representadas duas condições de organização da codificação (i.e., correspondente ou não correspondente). Já as barras, tal como indicado na legenda, dizem respeito a dois tipos de tarefa de recordação ("Nominal" e "Colaborativa") estando ainda representadas as barras de erro-padrão (i.e., standard error ou SE). As figuras que incluam gráficos de linhas ou colunas 
devem conter informação sobre a distribuição, habitualmente intervalos de confiança ou erro-padrão associados às médias.

\section{Discussão}

Após a apresentação dos resultados procede-se à avaliação e interpretação das suas implicações, especialmente no respeitante às hipóteses ou objectivos originais. Esta secção visa assim examinar, interpretar e inferir a partir dos resultados verificados (ou das conclusões alcançadas no caso de artigos não empíricos) e deve iniciar-se com uma afirmação clara relativamente ao suporte das hipóteses ou concretização dos objectivos. As semelhanças (ou diferenças) entre os resultados verificados e os patentes na literatura devem ser utilizadas para contextualizar, confirmar e clarificar as conclusões. No caso de as hipóteses não serem suportadas, podem ser propostas explicações post hoc, isto é, avançar de forma sustentada com explicações alternativas para os dados obtidos. É relevante evitar a repetição de informação: cada afirmação apresentada deve contribuir para a interpretação avançada pelo autor e para a compreensão do leitor. Caso esta secção seja muito breve e directa pode ser integrada numa secção "Resultados e Discussão" na qual se acrescenta esta discussão à descrição dos resultados (no caso de estudos empíricos). Em alguns artigos empíricos com vários estudos é frequente encontrar secções de "Resultados e Discussão" no final de cada estudo empírico e no final introduzir uma secção de "Discussão Geral".

Outros aspectos a discutir são as limitações do estudo (e.g., fontes de potencial enviesamento; imprecisão de medidas, etc.); mecanismos explicativos do impacto da intervenção ou manipulação (alternativos ao postulados inicialmente); generalização dos resultados (e.g., diferenças entre amostra e população-alvo). A discussão deverá terminar com um comentário acerca da relevância das evidências (retomar, por exemplo, a discussão da pertinência do tópico avançada na introdução, extrapolar para outros campos, etc.) a nível prático, teórico ou clínico, salientando ainda que questões permanecem sem resposta, ou que emergem dos resultados obtidos ou das conclusões retiradas.

\section{Lista de Referências}

Um dos aspectos mais explorados no Manual de Normas de Publicação da APA é a definição de estilos de citações e referências bibliográficas. O domínio destas normas é uma ferramenta essencial. Por um lado, enquanto autores de trabalhos académicos ou artigos científicos, permite-nos reco- 
nhecer as contribuições de outros autores, contextualizando a nossa própria contribuição para a literatura e evitando situações de plágio (incluindo auto-plágio, i.e., a apresentação de uma ideia já publicada pelo próprio autor como uma ideia nova). Por outro lado, enquanto leitores, ficamos aptos a identificar a fonte original e a sua tipologia específica, facilitando a sua recuperação no caso de pretendermos clarificar ou aprofundar um dado tópico.

As referências devem ser apresentadas numa secção própria, cujo objectivo é fornecer, de forma rápida e inequívoca, a informação necessária para a identificação (e eventual recuperação) de cada fonte utilizada na investigação e preparação do trabalho. A organização da lista obedece primariamente a um critério alfabético, segundo os apelidos do primeiro autor de cada documento. No caso de existirem diferentes trabalhos de um mesmo autor (ou autores), estes serão organizados por ordem cronológica (i.e., do mais antigo para o mais recente). Sublinhamos que um único autor tem sempre precedência (face a uma referência onde existe também um co-autor). No caso de existirem referências em que um autor colabora com outros, aplica-se o critério de ordenação alfabética de acordo com o apelido do segundo autor e assim sucessivamente.

A nível de formatação, a secção inicia-se numa página independente com o título "Referências", centrado na primeira linha. Deverá utilizar-se espaçamento duplo e avanço pendente (i.e., a primeira linha de cada referência alinhada à esquerda e as restantes indentadas). A Figura 5 ilustra uma lista de referências (que inclui os trabalhos citados como exemplo ao longo do presente artigo). 


\section{Referências}

Ageism (n.d.). In Merrian-Webster's Online Dictionary. Retrieved from http:/www.merriam-webster.com/dictionary/ageism American Psychological Association (2011). Coreers in psychology [PDF]. Retrieved from http://www.apa.org/careers/resources/guides/careers.asp

Arriaga, P. F., Arede, M., Ulrich, E., \& Martins, R. (2010). A importôncia das emoçð̌es na empaila face às vitimas no desejo de punir os perpetradores e na percepção de risco. Comunicação apresentada no VII Simpósio Nacional de Investigação em Psicologia, Braga, Portugal.

Bernardes, S. F., \& Lima, M. (2006). Age differences in control beliefs regarding health: Control, strategy and capacity. British Journal of Health Psychology, 11, 357-371. doi: 10.1348/135910705X70057

Buijs, A., Hovardas, T., Figari, H., Castro, P., Devine-Wright, P., Fischer, A., \& . . Selge, S. (2012). Understanding people's ideas on natural resource management: Research on social representations of nature. Society \& Natural Resources, 25, 1167-1181. doi: $10.1080 / 08941920.2012 .670369$

Calheiros, M. A., \& Monteiro, M. B. (2007). Relações familiares e práticas maternas de mau trato e negligência. Análise Psicológica, 25, 195-210. Retirado de http://www.scielo.gpeari.mctes.pt/pdf/aps/v25n2/v25n2a03

Correia, I. F. (2001). Concertos e desconcertos na procura de um mundo concertado: Crença no mundo justo, inocência da vítima e vitimização secundáría (Dissertação de Doutoramento). Instituto Universitário de Lisboa (ISCTE-IUL), Lisboa, Portugal.

Estereótipo (s.d.). In Dicionório Priberan da Lingua Portuguesa. Retirado de http://www.priberam.pt/dlpo/default.aspx?pal=estereótipo

Ferreira, M. B. (2004). Automaticity and cognitive control: A dual process opprocch to reasoning under uncertainty (Doctoral dissertation). Faculty of Psy chology, University of Lisbon, Lisbon, Portugal.

Garcia-Marques, L., Ferreira, M. B., \& Garrido, M. V. (2013). Processos de influência social. In J. Vala \& M. B. Monteiro (Eds.), Psicologia social ( $9^{\mathrm{a}}$ ed., pp. 245-324). Lisboa: Fundação Calouste Gulbenkian.

Garcia Marques, L., Ferreira, M. B., Nunes, L., Garrido, M. V., \& Garcia Marques, T. (2010). False memories and impressions of personality. Sacial Cognition, 28, 556-568. doi: 10.1521/soco. 2010.28.4.556

Garcia-Marques, L., Garrido, M. V., Hamilton, D. L. \& Ferreira, M. B. (2012). Effects of correspondence between encoding and retrieval organization in social memory. Joumal of Experimental Social Psychology, 48, 200-206. doi: $10.1016 /$ j.jesp. 2011.06 .017

Garrido, M. V., Azevedo, C., \& Palma, T. (2011). Cognição Social: Fundamentos, formulações actuais e perspectivas futuras. Psicologia, XXV, 113-157.

Garrido, M. V., Azevedo, C., Prada, M., \& Santos, S. (2011). Normas de valência e conteúdo espacial. Laboratório de Psicologia, 9, 6793.

Garrido, M. V., Garcia-Marques, L., \& Hamilton, D. L. (2012a). Enhancing the comparability between part-list cueing and collaborative recall. Experimental Psychology, 59, 199-205. doi:10.1027/1618-3169/a000144

Garrido, M. V., Garcia-Marques, L., \& Hamilton, D. L. (2012b). Hard to recall but easy to judge: Retrieval strategies in social information processing. Social Cognition, 30, 57-71. doi:10.1521/soco.2012.30.1.56

Garrido, M. V., Lopes. D., \& Calheiros, M. M. (2011). Estudo de adaptação e validação de um questionário de clima organizacional para organizações sociais. Psicologia, XXV, 139-166.

Haddock, G., \& Maio, G. R. (Eds.), Contemporary perspectives on the psychology of attitudes. New York: Psychology Press.

Lakoff, G. (1987). Women, fire, and dongerous things: What categories reveal about the mind. Chicago: The University of Chicago Press.

Lopes, D., Vala, J., \& Costa-Lopes, R. (2005). Social validation of everyday knowledge and the use of the heterogeneity norm: An application to prejudice chonge. Poster presented at the $14^{\text {th }}$ General Meeting of the European Association of Social Psychology, Wurzburg, Germany.

Marques, V. (2008, 16 de Outubro). Tenho um fraquinho por ti - As nove regras da atracção inicial. Sábado, 110-111.

Martins, A., \& Calheiros, M. (2012). Construction of a Self-Complexity Scale for Adolescents. Psychological Assessment, 24, $973-982$. doi: $10.1037 / \mathrm{a} 0028582$

Neves, J. G., Garrido, M. V., \& Simôs, E. (2008). Manual de competências pessocis, interpessoais e instrumentais - Teoria e prótica ( $2^{2}$ ed.) Lisboa: Ediçoes Sflabo.

Palma, T., Garrido, M. V., \& Semin, G. R. (2011). Grounding person memory in space: Does spatial anchoring of behaviors improve recall? European Journal of Sacial Psychology, 41, 275-280. doi: 10.1002/ejsp. 795

Petty, R. E., Brifiol, P., \& DeMarree, K. G. (2007). The Meta-Cognitive Model (MCM) of attitudes: Implications for attitude measurement, change, and strength. Social Cognition, 25, 657-686. doi: 10.1521/soco.2007.25.5.657

Prada, M. (2010). Alvos em movimento: O papel das características dos estímulos na primaçăo afectiva (Dissertação de Doutoramento) ISCTE- IUL, Lisboa, Portugal.

Prada, M., \& Domingos, A. (no prelo). Paradigma de primação afectiva. Laboratónio de Psicologia.

Prada, M., \& Garcia-Marques, T. (2008). Influência e Interferência: Cruzando dois paradigmas de primação afectiva. PsicologiaEmoção e comportamento social, Vol. XXII, 87-108.

Prada, M., \& Silva, R. (2010). Qual é coisa, qual é ela? Avaliação de valência e familiaridade de imagens de objectos desconhecidos. Laboratónio de Psicologia, 8, 151-170.

Schwarz, N. (2000). Attitude measurement. In A. E. Kazdin (Ed.), Encyclopediaof psychology (Vol. 1, pp. 313-317). Washington, DC/ New York, NY: American Psychological Association/ Oxford University Press.

Schwarz, N., \& Bohner, G. (2001). The construction of attitudes. In A. Tesser \& N. Schwarz (Eds.), Blackwell hondbook of social psychology: Intraindividual processes (pp. 436-457). Balden, MA: Blackwell Publishers.

Semin, G. R., Garrido, M. V., \& Palma, T. A. (no prelo). Interfacing body, mind the physical and the social world. In D. Carlston (Ed.), The Oxford hondbook of social cognition. New York, NY: Oxford University Press.

Semin, G. R., Garrido, M. V., \& Palma, T. A. (2012). Socially situated cognition: Recasting social cognition as an emergent phenomenon. In S. Fiske \& N. Macrae (Eds.). The SAGE handbook of social cognition (pp. 143-169). London, England: Sage Publications.

Vala, J., \& Monteiro, M. B. (Eds.) (2013). Psicologia social ( $9^{a}$ ed.). Lisboa: Fundação Calouste Gulbenkian.

Wegener, D. T., \& Carlston, D. E. (2005). Cognitive processes in attitude formation and change. In D. Albarracin, B. Johnson, \& M. Zanna (Eds.), The hondbook of ottitudes (pp. 493-542). Mahwah, NJ: Erlbaum.

Figura 5. Ilustração de uma lista de referências (trabalhos citados enquanto exemplos ao longo do presente artigo). 
De seguida revemos as regras que dizem respeito à construção de cada referência bibliográfica. Começaremos por definir a forma geral de referência (e ilustramos com exemplos de materiais em português e em inglês) dos seguintes tipos de material: (a) publicações periódicas; (b) livros, capítulos de livros e entradas em livros de referência; (c) dissertações; (d) conferências; e (e) fontes online.

Em todos os casos, pretende-se que a referência seja o mais completa possível, sem no entanto ser redundante. Uma das dificuldades que frequentemente surgem na realização das referências é a selecção de elementos a incluir, dada a vastidão de informação disponível nas bases de pesquisa relativas a um dado documento. Os elementos mais comuns são: informação relativa à autoria, data de publicação, e título do documento. Dependendo do tipo de material, existem outros elementos que devem ser incluídos (como o local de edição, a designação da empresa editora, etc.). As regras contemplam ainda a definição de pontuação específica, bem como aspectos gráficos (e.g., a utilização do tipo de letra em itálico) que procuraremos explicitar.

\section{Regras para a Elaboração de Referências Bibliográficas}

\section{Publicações Periódicas}

Por publicações periódicas entende-se todos os itens publicados de forma regular, tais como: revistas científicas (em inglês journals), jornais, revistas, etc. Os elementos utilizados para referenciar uma publicação deste tipo são: apelido do(s) autor(es), seguidos pelas suas iniciais, ${ }^{9}$ ano de publicação, título do artigo, título da publicação periódica (itálico), volume (itálico), ${ }^{10}$ página inicial e página final, doi. ${ }^{11}$ Segue-se a forma geral de referência e alguns exemplos:

${ }^{9}$ Sublinhamos que a ordem em que os autores surgem nas publicações deve ser respeitada, não devendo ser reorganizada de acordo com qualquer critério.

10 Ainda que infrequente, por vezes é necessário indicar também em que número do volume o artigo se encontra. Especificamente, inclui-se tal informação quando cada número de um dado volume se inicia na página 1. O trabalho de Daniel e Onwuegbuzie (2007) presente na secção de referências do presente artigo constitui um exemplo deste caso. Porém, geralmente, os diferentes números de um dado volume são paginados de forma contínua (por exemplo, se o número 1 do volume $\mathrm{X}$ termina na página 300 o número 2 desse mesmo volume iniciar-se-ia na página 301), dispensando a apresentação de informação relativa ao número do volume.

11 Digital Object Identifier, ou doi, refere-se a uma sequência alfanumérica única para identificar conteúdos e fornecer uma ligação permanente à sua localização na Internet. Deve ser incluído sempre que disponível. 
Autor, A. A., Autor, B. B., \& Autor, C. C. (ano). Título do artigo. Título da publicação periódica, $x x$, pp-pp. doi: $\mathrm{xx} . \operatorname{Xxxxxxxxx}$

Garrido, M. V., Garcia-Marques, L., \& Hamilton, D. L. (2012b). Hard to recall but easy to judge: Retrieval strategies in social information processing. Social Cognition, 30, 57-71. doi:10.1521/soco.2012.30.1.56

Ou seja, sabemos assim que o artigo intitulado "Hard to Recall but Easy to Judge: Retrieval Strategies in Social Information Processing" foi escrito por três autores (M. V. Garrido, L. Garcia-Marques e D. L. Hamilton), publicado em 2012 no volume 30 da revista científica Social Cognition, e é apresentado entre as páginas 57 e 71 . Como no presente artigo já havíamos citado um outro trabalho dos mesmo autores e do mesmo ano, torna-se necessário adicionar letras à data para diferenciá-los e permitir a sua identificação na lista de referências (i.e., a, b, c, etc. de acordo com a ordem em que são mencionados no texto).

É importante salientar que a pontuação (e.g., pontos a seguir a cada inicial, separação dos autores por vírgulas, etc.) e formatação específica que apresentamos constam das directrizes da APA, devendo ser criteriosamente respeitada. Por exemplo, apenas a primeira palavra do título do artigo se inicia com maiúscula ${ }^{12}$ a não ser que este contenha palavras habitualmente escritas com maiúsculas (como nomes próprios, de países ou organizações) ou contenha pontuação que indique o início de uma nova frase (como no exemplo). Note que apenas o título da publicação periódica e o respectivo volume são italicizados. Existem alguns casos que constituem excepções a esta forma geral de referência. Nomeadamente, se existem mais de sete autores, devem ser referidos os seis primeiros, colocando depois reticências e, por fim, o último autor. No exemplo que apresentamos de seguida, colaboraram oito autores. De acordo com a regra, omite-se então apenas o sétimo (no caso Mouro, C.).

Buijs, A., Hovardas, T., Figari, H., Castro, P., Devine-Wright, P., Fischer, A., \& ... Selge, S. (2012). Understanding people's ideas on natural resource management: Research on social representations of nature. Society \& Natural Resources, 25, 1167-1181. doi:10.1080/08941920.2012.670369

Algumas publicações (ou autores) disponibilizam versões preliminares dos artigos. Caso o manuscrito ainda esteja em fase de preparação, ou já tenha sido submetido para publicação, deve utilizar-se a forma de referência

12 Quando se menciona o título de um livro, ou artigo, no corpo do texto deve utilizar-se a capitalização do título. 
abaixo identificada. Note-se que nunca se identifica a revista científica ou a editora a que se submeteu o trabalho. Se desejarmos citar esse trabalho no texto, devemos indicar o ano da versão consultada.

Autor, A. A., Autor, B. B., \& Autor, C. C. (ano). Título do manuscrito. Manuscrito em preparação (ou Manuscrito submetido para publicação).

No caso de o artigo submetido já ter sido aceite para publicação mas ainda não ter sido impresso, como não existe ainda uma data de publicação deve indicar-se, no lugar do ano entre parêntesis, a expressão (in press) ou (no prelo), se o artigo for em português. No exemplo seguinte, ainda que saibamos em que revista será publicado o artigo, não está ainda disponível qual será o volume e o número de páginas:

Prada, M., \& Domingos, A. (no prelo). Paradigma de primação afectiva. Laboratório de Psicologia.

Em todo o caso, recomenda-se a actualização da lista de referências próximo da data de publicação ou de entrega do trabalho, de modo a citar a versão final dos documentos (i.e., já com a referência completa).

Se a publicação tem uma periodicidade muito frequente, como no caso de revistas ou jornais de comunicação social, ${ }^{13}$ é necessária a inclusão de mais informação relativa à data para permitir uma rápida identificação e recuperação do documento. Por exemplo, tratando-se de uma revista publicada semanalmente (e.g., Visão) ou de um jornal diário (e.g., Público), deverá incluir-se o dia da publicação:

Marques, V. (2008, 16 de Outubro). Tenho um fraquinho por ti - As nove regras da atracção inicial. Sábado, 110-111. ${ }^{14}$

13 Sublinhamos que, na maioria dos casos, é preferível citar revistas científicas. Porém, em alguns casos poderá ser pertinente citar fontes da comunicação social (e.g., para ilustrar um exemplo real num artigo sobre discriminação racial).

14 O artigo da revista Sábado que damos como exemplo foi baseado numa entrevista ao investigador David Rodrigues acerca do fenómeno de atracção interpessoal. Note-se, porém, que neste caso o autor é o jornalista (i.e., Vanda Marques). Um exemplo em que o investigador é também o autor é o caso dos artigos de opinião (e.g., coluna de Jorge Vala no Expresso). 


\section{Livros e Capítulos de Livros}

Esta secção inclui livros ou manuais sobre um dado tópico, bem como livros de referência tais como enciclopédias ou dicionários. Podemos diferenciar entre livros de autor (um ou vários) e livros editados (no qual uma ou várias pessoas são responsáveis pela organização do livro, podendo ser ou não autores de capítulos nesse mesmo livro). Outra distinção relevante é se pretendemos referenciar a totalidade do livro ou apenas um dos capítulos. Segue-se a forma geral de referência para os dois casos e alguns exemplos:

Autor, A. A. (ano). Título do livro. Local: Editora.

Neves, J. G., Garrido, M. V., \& Simões, E. (2008). Manual de competências pessoais, interpessoais e instrumentais - Teoria e prática ( $2^{\mathrm{a}}$ ed.) Lisboa: Edições Sílabo.

Ou seja, o livro intitulado "Manual de Competências Pessoais, Interpessoais e Instrumentais - Teoria e Prática" foi escrito por três autores (J. G. Neves, M. V. Garrido e E. Simões) e publicado em Lisboa pelas Edições Sílabo. Note-se que a data (i.e., 2008) corresponde à segunda edição desta obra. É essencial indicar a edição específica consultada dado que é comum a reestruturação e actualização de conteúdos entre diferentes edições de uma mesma obra. Apenas o título do livro é italicizado.

Editor, A. A. (Ed.). (ano). Título do livro. Local: Editora.

Vala, J., \& Monteiro, M. B. (Eds.) (2013). Psicologia social (9a ed.). Lisboa: Fundação Calouste Gulbenkian.

Neste caso, J. Vala e M. B. Monteiro são os editores da nona edição do livro Psicologia Social, editado em 2013, em Lisboa, pela Fundação Calouste Gulbenkian. Como podemos observar, a única diferença consiste em identificar os editores com a expressão "Eds." antes de se indicar a data.

Caso se pretenda citar apenas um capítulo, e não o livro inteiro, devemos começar pelo(s) autor(es) do capítulo específico, seguido(s) da data de publicação do livro e o título do capítulo. De seguida, indicamos o(s) nome(s) do editor(es), indicando primeiro a(s) sua(s) inicial(ais). Este caso é, aliás, o único previsto nas normas de referências em que as iniciais precedem o apelido do autor. Segue-se então a indicação que se trata(m) do(s) edi- 
tor(es) - (Eds.) -, o título do livro e as páginas em que o capítulo pode ser encontrado, bem como o local de edição e o nome da editora: ${ }^{15}$

Autor, A. A., \& Autor, B. B. (ano). Título do capítulo. In A. Editor \& B. Editor (Eds.), Título do livro (pp. xx-xx). Local: Editora.

Garcia-Marques, L., Ferreira, M. B., \& Garrido, M. V. (2013). Processos de influência social. In J. Vala \& M. B. Monteiro (Eds.), Psicologia social (9a ed., pp. 245-324). Lisboa: Fundação Calouste Gulbenkian.

Imagine agora que consultou um livro de referência, como uma enciclopédia de psicologia, com o objectivo de definir um dado conceito (e.g., medida de atitude). Neste caso, deverá referenciar essa entrada específica. Como pode observar no exemplo seguinte, a forma de referência é semelhante à de capítulo de um livro, correspondendo o nome da entrada ao título do capítulo. Note-se ainda que no exemplo que se segue são apresentados dois locais de edição dado que a publicação do livro resultou da colaboração de duas editoras (a APA e a Oxford University Press).

Schwarz, N. (2000). Attitude measurement. In A. E. Kazdin (Ed.), Encyclopedia of psychology (Vol. 1, pp. 313-317). Washington, DC/ New York, NY: American Psychological Association/ Oxford University Press.

Noutros casos, como quando a definição do conceito é consultada num dicionário, poderá não haver um autor ou editor identificado. Sendo uma edição online, também a data poderá não estar presente. Por exemplo, se consultou a definição de um termo (e.g., ageism ou estereótipo) num dicionário online (Merriam Webster ou Priberam), o nome do conceito ocupa o lugar habitualmente reservado para os autores. Tendo em conta que não existe uma data disponível utiliza-se a abreviatura "n.d". ou "s.d." para indicar "no date" ou "sem data". As referências relativas a estes termos seriam:

Ageism (n.d.). In Merriam-Webster's Online Dictionary. Retirado de [ou Retrieved from, se estiver a redigir o texto em inglês] http://www.merriam-webster.com/ dictionary/ageism

Estereótipo (s.d.). In Dicionário Priberam da Língua Portuguesa. Retirado de [ou Retrieved from, se estiver a redigir o texto em inglês] http://www.priberam.pt/ dlpo/default.aspx?pal=estereótipo

15 Quando o autor e a editora são a mesma entidade (por exemplo, o manual de normas é da autoria da APA e é também editado pela APA), deve usar-se a palavra Author ou Autor na secção da referência destinada à apresentação da editora. 
Destacamos que a definição apenas surge na lista de referências quando é efectivamente transcrita no texto (exclui-se assim as consultas ao dicionário efectuadas apenas para clarificar o significado de uma palavra na preparação do texto).

\section{Dissertações}

A consulta de dissertações de mestrado ou doutoramento é frequente sobretudo pela utilidade ao nível do mapeamento da literatura num dado campo. Apenas o nome do autor (i.e., o candidato ao grau) é referenciado, não sendo mencionado o nome do(s) orientador(es) do trabalho, seguindo-se a data e o título. Deve ainda ser indicado, entre parêntesis, a que tipo de dissertação se refere (i.e., Dissertação de Mestrado ou Master's thesis; Dissertação de Doutoramento ou Doctoral dissertation), bem como o nome da instituição que confere o grau e o nome da cidade e do país a que esta pertence. Segue-se o formato geral e alguns exemplos:

Autor, A. A. (ano). Título da dissertação (Tipo de dissertação: Mestrado ou Doutoramento). Nome da Instituição, Local.

Correia, I. F. (2001). Concertos e desconcertos na procura de um mundo concertado: Crença no mundo justo, inocência da vítima e vitimização secundária (Dissertação de Doutoramento). Instituto Universitário de Lisboa (ISCTE-IUL), Lisboa, Portugal.

Ferreira, M. B. (2004). Automaticity and cognitive control: A dual process approach to reasoning under uncertainty (Doctoral dissertation). Faculty of Psychology, University of Lisbon, Lisbon, Portugal.

\section{Conferências}

As actas (proceedings) de conferências podem ser publicadas em formato de livro ou publicação periódica (nessa situação aplicam-se as formas já definidas para esses casos). Caso as comunicações (orais ou em formato poster) não tenham sido formalmente publicadas deve seguir-se a seguinte formatação geral:

Apresentador, A. A. (ano, mês). Título da comunicação oral ou poster. Comunicação [ou poster] apresentada na conferência $x$, Local.

Arriaga, P. F., Arede, M., Ulrich, E., \& Martins, R. (2010, Fevereiro). A importância das emoções na empatia face às vítimas no desejo de punir os perpetradores e na percepção de risco. Comunicação apresentada no VII Simpósio Nacional de Investigação em Psicologia, Braga, Portugal. 
Lopes, D., Vala, J., \& Costa-Lopes, R. (2005, July). Social validation of everyday knowledge and the use of the heterogeneity norm: An application to prejudice change. Poster presented at the 14th General Meeting of the European Association of Experimental Social Psychology, Wurzburg, Germany.

\section{Fontes Online}

No respeitante às normas para material pesquisado e/ou obtido online, devemos em primeiro lugar identificar que tipo de material se trata. No caso de um documento (integral ou excerto) obtido num website, como um artigo científico sem doi disponível, devemos citá-lo no texto e incluí-lo na lista de referências. Para tal, utilizamos as regras já abordadas para cada tipo de material bibliográfico (e.g., artigo ou livro):

Calheiros, M. A., \& Monteiro, M. B. (2007). Relações familiares e práticas maternas de mau trato e negligência. Análise Psicológica, 25, 195-210. Retirado de www.scielo.gpeari.mctes.pt/pdf/aps/v25n2/v25n2a03

Noutros casos, a identificação não é óbvia. Regra geral, é preciso fornecer os quatro elementos de informação que se seguem.

Autor, A. (data). Título do documento [Descrição do formato]. Retirado de [ou Retrieved from] http://xxxxxxxxx

No exemplo seguinte trata-se de uma brochura da APA, acerca das diferentes áreas de aplicação da psicologia, disponibilizada em formato PDF no website indicado:

American Psychological Association (2011). Careers in psychology [PDF]. Retirado de [ou Retrieved from] www.apa.org/careers/resources/guides/careers.pdf

Por vezes, a informação não integra um documento específico, estando apenas presente numa dada página da Internet. Nesse caso, basta citá-la no texto não sendo necessário uma entrada na lista de referências. Por exemplo, imagine que se trata de um excerto da introdução de um trabalho:

"A existência de 56 divisões diferentes na APA (http://www.apa.org/about/division/ index.aspx) é ilustrativa da variedade de aplicações da psicologia."

Ou seja, no caso acima o autor apenas consultou o website da APA com vista a determinar quantas são as divisões que compõem a associação e utiliza essa informação para sustentar a afirmação de que a psicologia se caracteriza por uma grande diversidade de aplicações. 


\section{Citações no Texto}

Todas as fontes citadas no texto (identificação do autor e da data de publicação) surgem obrigatoriamente na secção de referências (e vice-versa). As únicas excepções a esta regra são as citações de trabalhos clássicos com secções estandardizadas e independentes da edição (e.g., Bíblia, Alcorão) e as referências a comunicações pessoais. ${ }^{16}$

Quando reproduzimos integralmente as palavras de um autor (ou, por exemplo, instruções dadas a participantes num estudo) devemos indicar não só o apelido do autor e a data, mas também a página específica em que o excerto está presente. Destacamos que a reprodução deve ser fiel ao original (em termos de idioma ${ }^{17}$, grafia, pontuação, gramática, etc.) mesmo se este contiver alguma incorrecção. Se considerarmos que uma eventual incorrecção poderá confundir o leitor deve colocar-se imediatamente a seguir ao erro a expressão latina "sic" (que significa "é assim") em itálico e entre parêntesis rectos. Este tipo de parêntesis também é utilizado quando adicionamos palavra(s) à citação com o intuito de a clarificar. Se desejarmos omitir material que consta na fonte original devemos assinalar a omissão utilizando três pontos espaçados (...) se a omissão é numa mesma frase e quatro pontos espaçados (...) se a omissão é entre duas frases (no texto não se incluem os parêntesis, apenas os pontos). Caso o excerto reproduzido seja inferior a 40 palavras, a citação pode ser incorporada no texto e apresentada entre aspas. Por exemplo, se a citação surge a meio de uma frase:

Garrido, Azevedo, Prada e Santos (2011) sugerem que "o próprio conteúdo espacial das palavras-estímulo utilizadas remete para diferentes localizações espaciais" (p. 70), logo...

Se surgir no final, a referência deve suceder à citação entre parêntesis como apresentado no exemplo seguinte.

16 Este tipo de citação é pouco frequente, mas pode ocorrer quando outro autor faz sugestões relevantes para um dado trabalho, por exemplo, aquando da apresentação num congresso. Dado que a informação contida em cartas, emails ou conversas não é acessível aos leitores, não consta da lista de referências, podendo apenas ser mencionada no texto da seguinte forma: "De acordo com T. Ramos (comunicação pessoal, 09 de Janeiro, 2007), os factores ..." ou "Os factores... (T. Ramos, comunicação pessoal, 09 de Janeiro, 2007)".

17 Se o original estiver numa língua diferente (e.g., inglês num artigo em português) pode incluir-se, se considerado útil, o material original entre aspas e depois a tradução entre parêntesis e sem aspas. Em alternativa poderá apresentar-se apenas a tradução, mas nesse caso já não se trata de uma citação directa uma vez que as traduções estão sujeitas à interpretação do tradutor. 
Tal poderá ser explicado porque "o próprio conteúdo espacial das palavras-estímulo utilizadas remete para diferentes localizações espaciais" (Garrido, Azevedo, Prada, \& Santos, 2011, p. 70).

Caso a citação seja mais extensa do que 40 palavras, deverá ser apresentada num bloco de texto independente, a espaçamento duplo, destacado e sem aspas:

Tais discrepâncias levaram Garrido, Azevedo, Prada e Santos (2011) a questionar:

se palavras positivas e negativas activam diferentes áreas do espaço visual devido à sua valência, tal como as propostas teóricas que tentam explicar estes efeitos parecem sugerir, ou porque o próprio conteúdo espacial das palavras-estímulo utilizadas (até agora não controlado) remete para diferentes localizações espaciais. (p. 70)

No exemplo acima a fonte é citada na afirmação que introduz o bloco de texto (daí que no final do bloco apenas seja necessário referir o número da(s) página(s) em que este se encontra). Em alternativa, a fonte pode ser citada no final do bloco.

Mais comum do que a reprodução textual das palavras de um autor é a citação das suas ideias. Neste caso não é necessário incluir o número de página nem utilizar aspas. A citação pode fazer parte da própria narrativa do texto:

Prada (2010) demonstrou que a primação afectiva é independente da familiaridade dos alvos.

Em alternativa, pode estar apenas indicada entre parêntesis:

A primação afectiva é independente da familiaridade dos alvos (Prada, 2010).

Enquanto o ano de publicação deverá ser sempre indicado, existem algumas variações relativamente à indicação dos autores consoante o seu número: (a) um ou dois autores, deve citar-se sempre o(s) seu(s) apelido(s), independentemente do número de vezes que aquele trabalho específico é citado; (b) três a cinco autores, deverá citar-se todos os apelidos apenas na primeira vez que o trabalho é referenciado, em referências subsequentes usar apenas o apelido do primeiro autor e a abreviatura "et al." ou, se for fora de parêntesis, a expressão "e colaboradores" (embora "et al." também possa ser usado), seguido da data; (c) seis ou mais autores, todas as referências (mesmo a primeira) seguem esta última regra.

Os nomes de grupos que asseguram a autoria de um trabalho (e.g., empresas, associações, centros de investigação, institutos) são habitualmente escritos por extenso sempre que citados, a não ser que a sua abreviatura seja familiar (e.g., INE) ou rapidamente compreensível (utilização possível a 
partir da segunda referência). Todos estes casos se encontram ilustrados no Quadro 4.

Quadro 4

Síntese dos Estilos de Citação no Texto para Diferentes Tipos de Trabalhos

\section{Citação na narrativa Citação entre parêntesis}

$\begin{array}{llll}\text { Tipo } & \text { Primeira } & \text { Seguintes } & \text { Primeira }\end{array}$

1 Trabalho,
1 Autor

1 Trabalho, Bernardes e Lima Bernardes e Lima (Bernardes \& Lima, (Bernardes \& Lima,

2 Autores (2006) 2006) 2006)

1 Trabalho, Neves, Garrido e

3 Autores Simões (2008)

1 Trabalho, Garrido, Azevedo,

4 Autores Prada e Santos (2011)

1 Trabalho, Garcia-Marques,

5 Autores Ferreira, Nunes, Garrido e Garcia-Marques (2010)

1 Trabalho, 6 Autores

Garrido et al., 2009 Garrido et al., 2009 al., 2010
(Neves, Garrido, \&

Simões, 2008)

(Neves et al., 2008)

(Garrido, Azevedo,

Garrido et al., 2011 Prada, \& Santos, 2011)

(Garrido et al., 2011)

(Garcia-Marques,

Garcia-Marques et Ferreira, Nunes, (Garcia-Marques et

Garrido, \& Garcia-

-Marques, 2010)

(Garrido et al., 2009)

(Garrido et al., 2009)

(INE, 2005)

(INE, 2005)

Grupos Instituto Nacional

abreviatura de Estatística (INE, INE (2005)

familiar 2005)

\section{Grupos}

abreviatura Fundação Champa- Fundação Champa- (Fundação Champa- (Fundação Champanão- $\quad$ limaud (2013) limaud (2013) limaud, 2013) limaud, 2013)

-familiar

Nota. Adaptado de Publication Manual of the American Psychological Association (p. 177), de APA, 2010, Washington, DC: Autor. Copyright 2010 da APA. 
É frequente verificarmos que a ideia que citamos está presente em múltiplos trabalhos existentes na literatura. Assim sendo, devemos ordenar a apresentação dessas múltiplas referências por ordem alfabética (tal como na lista de referências bibliográficas), e não por ordem cronológica, de importância ou qualquer outro critério:

Em consequência, a correspondência entre atitudes e avaliac,ões (e.g., Haddock \& Maio, 2004; Petty, Briñol, \& DeMarree, 2007; Wegener \& Carlston, 2005) ou julgamentos avaliativos (e.g., Schwarz \& Bohner, 2001) tem dominado as definiç̃os contemporâneas de atitudes.

Sendo dois ou mais trabalhos do(s) mesmo(s) autores, deverá seguir-se uma ordem cronológica. No exemplo que se segue, um dos trabalhos está publicado e o outro estaria no prelo:

... da cognição social situada (Semin, Garrido, \& Palma, 2012, no prelo).

Se os autores forem os mesmos (e na mesma ordem) e as datas de publicação forem iguais, devemos adicionar uma letra enquanto sufixo (a,b,c, etc.) depois do ano, de forma a diferenciar entre trabalhos (e incluí-los na lista de referências):

Vários estudos demonstram tal padrão de resultados (Garrido, et al., 2012a, 2012b)

Por último, revemos o caso em que a fonte é secundária (i.e., citamos um trabalho em segunda mão). Este tipo de referência deve ser utilizado com pouca frequência e apenas quando justificado (e.g., quando o trabalho original não está disponível nas fontes habituais, a edição foi descontinuada, não está disponível numa língua directamente acessível ao leitor, etc.). É essencial que fique claro no texto que o original não foi lido pelo autor e, para tal, introduz-se a expressão "citado por" ou "as cited in":

A perspectiva elementarista, que remonta aos filósofos britânicos dos séculos XVII e XVII, como Hume e Locke (citados por Garrido, Azevedo, \& Palma, 2011)...

Ou seja, neste caso como o autor não teria acesso às obras, poderá citá-las em segunda mão. Apenas a referência consultada aparece na lista de referências (i.e., Garrido, Azevedo, \& Palma, 2011).

\section{Comentário Final}

As orientações da APA para a escrita científica foram elaboradas sobretudo para promover uma comunicação científica forte, simples e elegante, maximizando assim a probabilidade de publicação. Neste artigo procurámos sistematizar as principais normas relativas à produção de escrita 
científica sugeridas pela APA (e clarificar dúvidas comuns) e, sempre que possível, ilustrando com casos adaptados para a língua portuguesa. Desta forma, esperamos ter contribuído para facilitar o processo de escrita académica no domínio da psicologia, em particular para os alunos e jovens investigadores que agora iniciam o seu percurso, para quem a leitura do manual de normas da APA possa parecer, num primeiro momento, desencorajadora pela sua extensão e complexidade. De facto, reconhecemos que nem todas as normas contribuem de igual forma para potenciar a clareza e objectividade da comunicação. Alguns aspectos poderão mesmo parecer triviais, o que habitualmente está na origem da resistência a aprofundar o conhecimento das normas (e.g., Beins, 2006). Porém, estamos seguras de que os benefícios ao nível da qualidade da produção científica justificam o investimento.

Muitos são os aspectos que, por uma questão de parcimónia, não foram aqui contemplados. Por exemplo, ao nível da elaboração de referências bibliográficas, não contemplámos as normas relativas a outros tipos de fontes como filmes, música, ou fotografia. Para um domínio das normas é essencial a consulta do manual (APA, 2010a) que, certamente, estará disponível nas bibliotecas institucionais. Um outro recurso de grande utilidade é o website da APA dedicado a este tópico (www.apastyle.org/) onde podem ser encontrados tutoriais de iniciação às normas. Sugerimos ainda a consulta do blogue (http://blog.apastyle.org/), centrado no estilo da APA, onde se podem encontrar esclarecimentos face a situações menos comuns ou menos claras no manual, ou mesmo a respectiva página do Facebook (www.facebook. com/APAStyle). Ambas as opções permitem interagir com especialistas em normas e colocar questões. Outra opção será consultar informação disponível em websites (e.g., Laboratório de Escrita da Universidade de Purdue http://owl.english.purdue.edu/owl/resource/560/01/), que apresentam uma síntese fiável das normas.

Salientamos ainda que o estilo da APA é actualmente adoptado pela maioria dos autores, editores, professores e estudantes no âmbito das ciências sociais e comportamentais. No entanto, e não obstante a utilidade das orientações da APA e da sua ampla adopção por parte da maioria das publicações científicas na área da psicologia, quando um autor submete um artigo a uma revista científica deverá sempre assegurar-se que segue as recomendações descritas nas políticas de submissão dessa publicação específica. Do mesmo modo, na preparação de dissertações ou trabalhos académicos para unidades curriculares específicas o autor deve sempre consultar o professor supervisor para especificar as orientações de estilo pretendidas. O mesmo se aplica à redacção de propostas ou projectos submetidos a concursos específicos, que embora possam beneficiar do estilo de escrita e formatação recomendados pela APA deverão ser preparadas de acordo com as normas e regulamentos referidos nas orientações de candidatura divulgadas. 
Por último, relembramos que "a prática leva à perfeição". Neste sentido, é nossa expectativa que o presente artigo contribua para que, dominando estas orientações, os leitores se aventurem com sucesso na publicação dos seus trabalhos de investigação.

\section{Referências}

American Psychological Association (2010a). Publication manual of the American Psychological Association (6 ${ }^{\text {th }}$ ed.). Washington, DC: Author.

American Psychological Association (2010b). Ethical principles of psychologists and code of conduct [PDF]. Retirado de www.apa.org/ethics/code/ principles.pdf

Beins, B. C. (2006). Writing in APA style: The style we love to hate. The General Psychologist, 41(2), 33-35.

Bentley, M., Peerenboom, C. A., Hodge, F. W., Passano, E. B., Warren, H. C., \& Washburn, M. F. (1929). Instructions in regard to preparation of manuscript. Psychological Bulletin, 26, 57-63. doi: 10.1037/ h0071487

Correia, I., Lima, L., Lopes, D., \& Mouro, C. (2010). Guião para o Estilo de Escrita da APA (versão para a $6^{a}$ edição). Manuscrito não publicado, Departamento de Psicologia Social e das Organizações, ISCTE-IUL, Lisboa, Portugal.

Daniel, L. G., \& Onwuegbuzie, A. J. (2007). Editorial: Effective use of APA style in manuscript preparation. Research in the Schools, 14(1), i-x.

Gribbin, J. (2005). História da ciência: De 1543 ao presente. Lisboa: Europa-América.

Ordem dos Psicólogos Portugueses (2011, 20 Abril). Código Deontológico da Ordem dos Psicólogos Portugueses. Diário da República, $2^{a}$ série, 17931-17936. Retirado de www.ordemdospsicologos.pt/ficheiros/documentos/ caodigo_deontolaogico.pdf

Sigal, M. J., \& Pettit, M. (2012). Information overload, professionalization, and the origins of the Publication Manual of the American Psychological Association. Review of General Psychology, 16, 357-363. doi: 10.1037/a0028531 